\title{
Development of the "Scale of Identity Adaptation (SIA)" for People with Schizophrenia \\ Hitomi Setoguchi
}

Department of Nursing, School of Health Science, Saitama Prefectural University, Saitama, Japan

Abstract

Objective: People with schizophrenia "adapt their identity" to the illness in order to live on their own in the community, which is considered essential. The aim of the present study was to measure and report the reliability of the original Scale of Identity Adaptation (SIA) for people with schizophrenia.

Method: Several social welfare corporations (welfare facilities), psychiatric clinics, and associations for patients with schizophrenia or their families in the Kanto area in Japan volunteered to participate. A total of 265 anonymous, self-administered questionnaires were mailed to the 10 facilities, which approved the research and agreed to refer research participants.

Results: Of the 265 questionnaires mailed, responses were collected from 87 participants (response rate = $33 \%$ ). Among these, valid data of 77 participants were used for analysis (response rate $=89 \%$ ), after deleting questionnaires with missing data. The sample consisted of 42 men (55\%), 30 women (39\%), and 5 non-responses (6\%). The median age was 48 years (range: $20-80$ years); the mean age was 48.5 ( \pm 2.12 ) years for men, and 45.7 $( \pm 15.56)$ years for women. Four factors were extracted from the 33 items of the SIA draft through primary factor analysis (Promax rotation). For the 33 items of the draft, exploratory factor analysis was performed for 18 items using item analysis. The Cronbach's reliability coefficient for the four-factor structure was $0.83 \sim 0.90$, confirming reliability.

Conclusions: The SIA developed in this study comprised four factors and 24 items; the SIA's reliability was verified as the Cronbach's a was found to be 0.75 or greater for the entire scale.

\section{Background}

Mental illnesses follow a chronic course and once afflicted, patients must live with them long term. Among mental illnesses, schizophrenia not only has a high rate of hospitalization, but the hospitalizations tend to be long-term, with over 200,000 patients having a hospital stay of over one year. The Ministry of Health, Labour and Welfare in Japan published the "Mental Healthcare Reform Vision" with the aim of shifting from inpatient focused care to "the realization of a society of coexistence based in the community" [1]. While this publication encouraged a transition to community-based society, it included standards for arranging psychiatric hospital beds and extending hospital stays for older adults, over the age of 65 . Further, at least 70,000 patients remain "socially hospitalized," a phenomenon in which impaired patients whose conditions are stable and do not require medical treatment are hospitalized for long periods [2] reflecting the unresolved status of this situation [3]. Individuals with chronic illnesses must modify their daily activities to control their symptoms if they wish to live a normal life. Corbin and Strauss referred to "identity adaptation" as the process of modifying one's identity, which becomes necessary when one lives with a chronic illness [4]. In the past, individuals with schizophrenia were thought to have a reduced capacity to perceive themselves objectively because of their illness [5] and were consequently refused the opportunity to talk about themselves [6]. However, recent studies have revealed how those with schizophrenia perceive their disorder and the significance of their illness in their own words. It has become clear that those with schizophrenia, experience "suffering from the illness itself," "suffering to rebuild the self," and "suffering due to experiences of hospitalization and medication," in the process of achieving recognition of their illness and its significance [7-9]. Much like patients themselves describe that "no one led me by the hand" to "take back and rebuild myself," [7] there are few reports from the medical side providing support for rebuilding the self; in other words, there are few resources to aid in achieving identity adaptation. Nonetheless, it is obvious from patients' testimonies that they have struggled to overcome the pain on their own and to rebuild themselves, and that this support is needed. Although providing support to help people with schizophrenia adapt their identity to their illness is considered essential, concrete methods to do so have not yet been established.

In the field of nursing science, studies on the concept of identity adaptation have been conducted with a variety of patients with chronic illnesses, including cancer care patients, [10-12] older adults, [13,14] and diabetics [15]. Modifying identity, i.e. identity adaptation, is essential when one lives with a chronic illness. Although schizophrenia is also a chronic illness, there are striking individual differences due to the diversity of symptoms, and the condition is often difficult to live with even after many years. This may also be in part due to the lack of specific established support methods discussed above. Successful identity adaptation to the illness allows people with schizophrenia to live in their own way and may contribute to improving their quality of life. Setoguchi et al. performed concept analysis of 32 Japanese and 2 English papers on identity adaptation to the illness and defined the following process: "Patients follow a course of [coexistence with the illness], [positive perception of self], [way of socializing with family and others that is suited to the current self], [acquisition of new values], and [improved self-monitoring], which leads them to [living in their own way]" [16]. However, there is no effective support found "Corresponding Author: Prof. Hitomi Setoguchi, Department of Nursing, School of Health Science, Saitama Prefectural University, Saitama, Japan; E-mail: setoguchi-hitomi@spu.ac.jp

Citation: Setoguchi H (2021) Development of the "Scale of Identity Adaptation $(\text { SIA })^{\prime \prime}$ for People with Schizophrenia. Int J Nurs Clin Pract 7: 335. doi: https://doi. org/10.15344/2394-4978/2021/335

Copyright: (C) 2021 Setoguchi. This is an open-access article distributed under the terms of the Creative Commons Attribution License, which permits unrestricted use, distribution, and reproduction in any medium, provided the original author and source are credited. 
Citation: Setoguchi H (2021) Development of the "Scale of Identity Adaptation (SIA)" for People with Schizophrenia. Int J Nurs Clin Pract 7: 335. doi: https:// doi.org/10.15344/2394-4978/2021/335

Page 2 of 5

for adapting their identity to the illness in order to "live in their own way" in the community. Therefore, the aim of the present study was to measure and report the reliability of the original Scale of Identity Adaptation (SIA) for people with schizophrenia.

\section{Method}

\section{Development of the scale draft of SIA}

\section{Review of structural concepts}

A previous study assessing the process of identity adaptation in community-dwelling people with schizophrenia found that they had developed an acceptance of the illness as a result of the support from family, friends, and doctors/nurses. This acceptance of the illness, along with self-control and changing one's thinking, led to the realization of social roles and activities, and development of career as purpose in life; these made them feel that they were enjoying life, happy, and free [17].

\section{Drafting questions about "identity adaptation" to the illness}

Items representing identity adaptation were extracted from previous studies. Additional questions were drafted through a brainstorming session with 15 nursing university faculties, including two work-life balance (WLB) researchers and mental health professionals, about the circumstances and behaviors indicating that an individual has accomplished identity adaptation. Items were evaluated on a 6-point Likert scale consisting of "completely disagree" (1 point), "disagree" (2 points), "if I had to choose, I disagree" (3 points), "if I had to choose, I agree" (4 points), "agree" (5 points), and "completely agree" (6 points).

\section{Validity testing and item revision}

Face validity and content validity were tested. A group of 14 nursing university faculty, including nurses in various positions (head nurse, charge nurse, or staff nurse), with at least five years of clinical experience; one WLB researcher; and mental health professionals, checked for semantically unclear questions, duplicate items, or

\begin{tabular}{|c|c|c|}
\hline \multirow{4}{*}{$\begin{array}{l}\text { Acceptance of the } \\
\text { illness }\end{array}$} & 1 & I can now understand the circumstances of when I was hospitalized \\
\hline & 2 & I accept my condition in my own way \\
\hline & 3 & I think there is meaning in everything that has happened to me \\
\hline & 4 & I think it's good that I'm this type of person \\
\hline \multirow{5}{*}{$\begin{array}{l}\text { Acquisition of family, } \\
\text { friend, and doctor/ } \\
\text { nurse support }\end{array}$} & 5 & I have family members who understand me \\
\hline & 6 & There are people who seem to understand who I am \\
\hline & 7 & I willingly try to start conversations to get people to understand me \\
\hline & 8 & There are places where I feel I'm allowed to be and where I can have peace of mind \\
\hline & 9 & There are people I can go to for advice when I'm having trouble \\
\hline \multirow[t]{5}{*}{ Self-control } & 10 & I have asked my doctor to adjust the dosage of my medication \\
\hline & 11 & I have learned about the symptoms of my illness \\
\hline & 12 & I can find ways to cope with my symptoms in my own way \\
\hline & 13 & I try to change the way I'm feeling \\
\hline & 14 & I can seek help when I'm not doing well \\
\hline \multirow{4}{*}{$\begin{array}{l}\text { Changing one's } \\
\text { thinking }\end{array}$} & 15 & I can change my mood even when things I don't like, happen or when things don't go as I want \\
\hline & 16 & I believe thinking too much won't change anything, whatever happens, happens \\
\hline & 17 & I try to enjoy what I experience at those times \\
\hline & 18 & My way of thinking became more positive because of my experience with illness \\
\hline \multirow{4}{*}{$\begin{array}{l}\text { Acquisition of social } \\
\text { roles and activities }\end{array}$} & 19 & It's fun to participate in activities in the community, etc. \\
\hline & 20 & I can work with others during activities in the community, etc. \\
\hline & 21 & I can participate in social activities as much as I am able \\
\hline & 22 & I can show interest in people's concerns and offer advice \\
\hline \multirow{4}{*}{$\begin{array}{l}\text { Career as a purpose } \\
\text { in life }\end{array}$} & 23 & I can make my work fun \\
\hline & 24 & I collaborate with others in my work \\
\hline & 25 & I'm satisfied with my job \\
\hline & 26 & I want to do my job \\
\hline \multirow[t]{3}{*}{ Enjoying life } & 27 & I enjoy my hobbies \\
\hline & 28 & My life is fun because I can do things, I like \\
\hline & 29 & I wake up when I want, I sleep when I want; I live my life how I want \\
\hline \multirow[t]{4}{*}{ Being happy now } & 30 & I can think about my future \\
\hline & 31 & I'm satisfied with my current life \\
\hline & 32 & I want to live each day like it's my last \\
\hline & 33 & I often feel happy now \\
\hline
\end{tabular}

Table 1: First Draft of the SIA. 
expressions that would be difficult to answer. They then confirmed that the content would measure identity adaptation. As a result, a total of 33 questions about identity adaptation to the illness were chosen, including four items on acceptance of the illness, five items on family support, friend support, doctor/nurse support; five items on selfcontrol, four items on changing one's thinking, four items on social roles and activities, four items on career as purpose in life, three items on enjoying life, and four items on being happy now (see Table 1).

\section{Survey}

\section{Participants}

Participants were 265 individuals from 10 facilities who lived in the community and either regularly visited a social welfare corporation (welfare facility) or a psychiatric clinic or agreed to participate in a meeting for patients with schizophrenia.

\section{Survey method}

1. An anonymous, self-administered questionnaire survey was conducted.

2. Survey period: Administered from October 2018 to March 2019.

3. Survey content

1. Participant attributes: sex, age, age at onset, experience with hospitalization, number of hospitalizations, use of oral medication, whether they live with others, and current activities (e.g., patient association activities, etc.)

\section{2. "Scale of Identity Adaptation (SIA)" to the Illness}

Items representing identity adaptation were extracted from past research. Additional items were drafted through a brainstorming session by a group of 15 nursing university faculty about circumstances and behaviors which are thought to indicate that an individual has accomplished identity adaptation. These items were used to create the first draft of the questionnaire. Items were evaluated on a 6-point Likert type scale consisting with ranging from "completely agree (6 points)" to "completely disagree (1 point)". A higher score indicates a higher degree of identity adaptation to the illness.

\section{Statistical analysis}

Descriptive statistics, reliability analysis, and validity analysis were conducted to analyze the data. Descriptive statistics were calculated to explain the main characteristics of the participants. Internal consistency reliability was assessed using Cronbach's alpha. Ceiling and floor effects as Item analysis, exploratory factor analysis (promax rotation) as reliability testing for SIA (draft) and their Cronbach's reliability coefficients were used to estimate reliability.

Bartlett's test of sphericity and KMO (Kaiser-Meyer-Olkin) measure of sampling adequacy were used to support usefulness of factor solution. Data were analyzed using SPSS version 22.0 (Version 25.0). The significance level was set at $\mathrm{p}<0.05$.

\section{Ethical considerations}

An explanation of the study was given, both orally and in writing, to the directors of the organizations that participants were affiliated with, and their consent was obtained. Participants were given a written summary of the study, its objective, methods, and the following ethical considerations: they were assured that anonymity would be maintained when results were published; survey participation was voluntary; there would be no disadvantages to refusing participation or not providing consent; the data would be statistically processed such that individuals would not be identified; and that the data would not be used for any reason except for the objective of the study. Furthermore, how survey forms and data would be managed were clearly specified in writing and the researcher gave their word that they would take meticulous care. The survey form was anonymous, and it was explained that the participant could also choose to mail in a blank form. This research was carried out after receiving approval from the ethics committee of Shumei University (23 October 2018; confirmation number: 18E002A).

\section{Results}

\section{Response rate}

Survey forms were distributed to 265 individuals from 10 facilities who lived in the community while regularly visiting a social welfare corporation (welfare facility) or a psychiatric clinic or agreed to participate in a meeting for people with schizophrenia or their families. A total of 87 responses (response rate 33\%) were collected by mail. Ten of these were excluded owing to missing data, leaving 77 valid responses (response rate $89 \%$ ) for analysis.

\section{Participant attributes}

Participants comprised of 42 men (55\%), 30 women (39\%), and 5 who did not respond (6\%). The median age was 48 years (range: $20-80$ years). The mean age was 48.5 years for men and 45.7 years for women. Most participants were between the ages of 40-49 $(n=28)$, followed by $50-59(n=20)$, and $30-39(n=13)$.

\section{Analysis}

\section{Ceiling and floor effects}

Item 5 "I have family members who understand me" $(M=6.11)$ and item 10 "I have asked my doctor to adjust the dosage of my medication" $(M=6.02)$ had a mean \pm SD of 3.0 or higher, demonstrating ceiling effects; therefore, they were removed. No items demonstrated floor effects.

\section{Reliability testing}

\section{Exploratory factor analysis (Table 2)}

For the remaining 31 items of the SIA (draft), four factors were extracted by the principal factor method (promax rotation). With a factor loading of 0.35 or greater as the adaptation criterion, 7 items were removed from the 31 items of the draft, and 24 items were subjected to exploratory factor analysis. The removed items were: 1 . "I can now understand the circumstances of when I was hospitalized," 2. "I accept my condition in my own way," 7. "I willingly try to start conversations to get people to understand me," 11. "I have learned about the symptoms of my illness," 14. "I can seek help when I'm not doing well," 29. "I wake up when I want, I sleep when I want; I live my life how I want," and 33. "I feel happy now." The extracted factors were: Factor 1 ssense of belonging and activities giving peace of mind\}, Factor 2 \{job satisfaction and career\}, Factor 3 \{having people they can trust\}, and Factor 4 \{enjoying life) and their Cronbach's reliability 
coefficients were $0.85,0.80,0.83$, and 0.80 , respectively. The KaiserMeyer-Olkin Measure of Sampling Adequacy was 0.640.

\section{Discussion}

\section{Reliability of the SIA concepts}

In the present study, an original scale was developed from past research and literature and confirmed through item analysis and exploratory factor analysis; it comprises 24 items and 4 factors. Cronbach's reliability coefficient was 0.85 for Factor 1, 0.80 for Factor 2, 0.83 for Factor 3, and 0.80 for Factor 4. Reliability is higher as the reliability coefficient approaches 1 [17]. Thus, the scale's internal consistency was verified.

Exploratory factor analysis did not extract eight factors corresponding to the concepts established in previous studies, i.e., [acceptance of the illness], [family support, friend support, doctor/ nurse support], [self-control], [changing one's thinking], [social roles and activities], [career as purpose in life], [enjoying life], and [being happy now]. Instead, the following four factors were extracted: Factor 1-sense of belonging and activities giving peace of mind, Factor 2-job satisfaction and career, Factor 3-having people they can trust, and Factor 4-enjoying life. Factor 1 was similar to the items of acceptance of the illness, changing one's thinking, and social roles and activities. Factor 2 included career as purpose in life; while Factor 3 included items of family support, friend support, doctor/nurse support. Factor 4 was similar to enjoying life and being happy now, but also included item 12 "I can find ways to cope with my symptoms in my own way" from self-control.

\section{Components of the SIA}

According to a previous study, "patients follow a course of [coexistence with the illness], [positive perception of self], [way of socializing with family and others that is suited to the current self], [acquisition of new values], and [improved self-monitoring], which leads them to [living in their own way]," [15] and the four factors: \{sense of belonging and activities giving peace of mind\}, \{job satisfaction and career\}, \{having people they can trust\}, and \{enjoying life\} have been identified as the factors of the SIA. In \{sense of belonging and activities giving peace of mind\}, individuals find their place through the self, as their perspective has been changed through the illness and through the activities in which they have been able to participate. In job satisfaction and career, individuals gain satisfaction from their jobs. This is considered an important factor, as no previous study has considered work to be a related factor. In having people they can trust, items indicating that one respects the self as well as cares about others: "I want to live each day like it's my last" and "I can think about my future," were observed. In enjoying life, satisfaction with their life was observed from items including "my life is fun" and "I'm satisfied with my current life."

\begin{tabular}{|c|c|c|c|c|c|c|}
\hline & \multirow[t]{2}{*}{ Item } & \multicolumn{4}{|c|}{ Factor loading } & \multirow[b]{2}{*}{ a coefficien } \\
\hline & & 1 & 2 & 3 & 4 & \\
\hline \multirow{9}{*}{$\begin{array}{l}\text { Factor 1: } \\
\text { Sense of } \\
\text { belonging and } \\
\text { activities giving } \\
\text { peace of mind }\end{array}$} & I can work with others during activities in the community & 0.764 & -0.129 & 0.186 & -0.204 & \multirow[t]{9}{*}{0.851} \\
\hline & I participate in activities in the community, etc. & 0.698 & -0.125 & 0.247 & -0.212 & \\
\hline & There is meaning in everything that has happened to me & 0.684 & -0.073 & -0.123 & 0.038 & \\
\hline & I participate in social activities as much as I am able & 0.661 & -0.109 & 0.209 & 0.045 & \\
\hline & There are places where I feel I'm allowed to be & 0.592 & -0.176 & 0.208 & -0.255 & \\
\hline & I think it's good that I'm this type of person & 0.589 & 0.075 & -0.305 & 0.296 & \\
\hline & I enjoy what I experience at those times & 0.584 & -0.01 & 0.023 & 0.27 & \\
\hline & I can change my mood & 0.536 & 0.12 & 0.055 & 0.155 & \\
\hline & My way of thinking became positive because of my experience with illness & 0.523 & 0.442 & -0.131 & 0.006 & \\
\hline \multirow{4}{*}{$\begin{array}{l}\text { Factor } 2 \text { : } \\
\text { Job satisfaction } \\
\text { and career }\end{array}$} & I can make my work fun & -0.132 & 0.973 & -0.015 & -0.047 & \multirow[t]{4}{*}{0.803} \\
\hline & I collaborate with others in my work & 0.104 & 0.91 & 0.01 & -0.298 & \\
\hline & I'm satisfied with my job & -0.053 & 0.856 & -0.053 & 0.002 & \\
\hline & I want to do my job & -0.22 & 0.447 & -0.021 & 0.028 & \\
\hline \multirow{5}{*}{$\begin{array}{l}\text { Factor 3: } \\
\text { Having people } \\
\text { they can trust }\end{array}$} & There are people I can go to for advice when I'm having trouble & 0.027 & -0.061 & 0.941 & -0.142 & \multirow[t]{5}{*}{0.828} \\
\hline & There are people who understand who I am & 0.021 & -0.067 & 0.624 & 0.109 & \\
\hline & I want to live each day like it's my last & -0.011 & 0.409 & 0.428 & 0.262 & \\
\hline & I can think about my future & 0.229 & 0.071 & 0.407 & 0.074 & \\
\hline & I can show interest in people's concerns and offer advice & 0.203 & 0.211 & 0.356 & 0.151 & \\
\hline \multirow{6}{*}{$\begin{array}{l}\text { Factor 4: } \\
\text { Enjoying life }\end{array}$} & I try to change the way I'm feeling & -0.365 & -0.161 & 0.076 & 0.95 & \multirow[t]{6}{*}{0.795} \\
\hline & I can find ways to cope with my symptoms in my own way & 0.051 & -0.206 & 0.364 & 0.576 & \\
\hline & I believe whatever happens, happens & 0.374 & -0.201 & -0.294 & 0.567 & \\
\hline & I enjoy my hobbies & -0.079 & 0.117 & 0.055 & 0.513 & \\
\hline & My life is fun because I can do things I like & 0.225 & 0.224 & 0.115 & 0.476 & \\
\hline & I'm satisfied with my current life & -0.02 & 0.124 & 0.28 & 0.473 & \\
\hline
\end{tabular}

Table 2: Exploratory factor analysis of the Scale of Identity Adaptation to the Illness. 
By investigating these four factors, it becomes possible to evaluate the life of people with schizophrenia in the community. It might be possible to provide support for those aspects represented by the items that score low on satisfaction. As a result, it is possible that this scale can contribute to their continued living in the community and the improvement of their quality of life.

\section{Research limitations}

Although this study examined the reliability of the SIA, however no confirmatory factor analysis has been performed, the goodness of fit of models is unknown. In addition, there is a limitation regarding the generalization of the scale because participants were from a particular area. Future studies should include samples from diverse areas.

\section{Conclusion}

The SIA developed in this study comprised of four factors and 24 items; and reliability were verified, with the Cronbach's $\alpha$ being 0.75 or greater for the entire scale. By using this scale, it is possible to evaluate the quality of life and provide support for people with schizophrenia showing lower satisfaction.

\section{Competing Interests}

The author declare that there is no competing interests regarding the publication of this article.

\section{Acknowledgements}

The author would like to offer their deepest appreciation to everyone who completed the survey and all facility representatives.

\section{Funding}

This study was supported by a Grant-in-Aid for Scientific Research (basic type C).

\section{References}

1. Ministry of Health, Labor and Welfare (2020) Mental Healthcare Reform Vision.

2. https://stti.confex.com/stti/congrs12/webprogram/Paper50556.html

3. Ministry of Health, Labor and Welfare (2020) Toward Further Mental Healthcare Reform.

4. Kuroe Y, Ichihashi K, Takarada M (1995) The Chronic Illness Trajectory Framework: The Corbin and Strausse Nursing Model. Tokyo: Igaku-Shoin.

5. Hoffman RE, McGlashan TH (1994) Corticocortical connectivity, Autonomous Networks, and schizophrenia. Schizophr Bull 20: 257-226.

6. Ishihara K (2013) Studies on Tojisha-Kenkyu. Tokyo: Igaku-Shoin, Ltd.

7. Tanaka M (2000) The significance of the illness as seen by one individual with a mental disorder: Community-dwelling patient N's life story and its interpretation. Nursing Research 33: 37-58

8. Tanaka M (2002) The life story of one individual with a mental disorder and its interpretation (Part 1)-Factors enabling community living and the relationship between personal history and the illness. Bulletin of the School of Nursing, Tokyo Women's Medical University 5: 1-15.

9. Tanaka M (2002) The life story of one individual with a mental disorder and its interpretation (Part 2)-The significance of the illness: The struggle to find independence and the significance of one's own existence. Bulletin of the School of Nursing, Tokyo Women's Medical University 5: 17-26.

10. Fujita $S$ (2001) Mastery of stress in cancer survivors. Journal of Kochi Women's University Academy of Nursing 26: 1-12.
11. Nakamura S, Kamizato M (2010) The coping behaviors on physical and psychosocial distress of daily living among breast cancer patients with lymphedema. Journal of Okinawa Prefectural College of Nursing 11: 1-13.

12. Nagasaka I, Majima T (2013) Development of a nursing intervention to help women with breast cancer deal with uncertainties while undergoing chemotherapy. Journal of Japanese Society of Cancer Nursing 27: 21-30.

13. Chiba K, Nakamura M, Nagae H (2002) The psychological process of "life harmony" in elderly post-operative hip fracture patients in the three months after discharge. Bulletin of Japanese Red Cross Musashino Junior College of Nursing 15: 83-88.

14. Nagae H, Chiba K, Nakamura M (2001) A study on disabled elderly women who live alone in the community: The concept structure of "the harmonious life". Journal of Japan Academy of Community Health Nursing 3: 123-130.

15. Tsuchida T, Fukushima $O$ (2006) A study on "living together with illness" for diabetes mellitus patients. Mejiro University Psychology Research 2: 25-33.

16. Setoguchi H, Itomine I, Asakura C (2017) Concept analysis of "coming to terms" with illness of people with schizophrenia. Japanese Journal of Human Sciences of Health-Social Services 23: 35-45.

17. Setoguchi H, Suzuki E (2018) The Process of Identity Adaptation (Oriai) in Community-Dwelling People with Schizophrenia. 6th Annual Worldwide Nursing 7: 24-27

18. Questionnaire surveys and data analysis for nurses. 2nd edition. IgakuShoin, Ltd. Japan.
This article was originally published in a special issue:

Psychiatric and Mental Health Nursing

Handled by Editor(s):

Prof. Tetsuya Tanioka

Department of Nursing Outcome Management

Tokushima University

Japan 